\title{
Evaluación electroforética del perfil proteico de lactosuero modificado mediante un sistema bioelectroquímico batch
}

\author{
Grisell Gallegos Ortega a,1, María Aurora Veloz Rodríguez a,2*, Victor Esteban Reyes Cruz a,3, José Angel Cobos Murcia a,b,4, \\ Luis Guillermo González Olivares ${ }^{c, 5}$, Emmanuel Pérez Escalante ${ }^{c, 6}$, Josephine Inés Quirino Gutiérrez ${ }^{\text {a,7 }}$, Omar Rosales \\ González ${ }^{\mathrm{a}, 8}$, Jaret del Carmen Ramírez Castellanos ${ }^{\mathrm{a}, 9}$. \\ ${ }^{a}$ Universidad Autónoma del Estado de Hidalgo, Área Académica de Ciencias de la Tierra y Materiales, Carr. Pachuca-Tulancingo km 4.5 s/n, Mineral de la Reforma, \\ Hidalgo, México. \\ ${ }^{b}$ Consejo Nacional de Ciencia y Tecnología, Depto. De Cátedras, Av. Insurgentes Sur 1582, Col. Crédito constructor, Deleg. Benito Juárez, Ciudad de México, C.P. \\ 03940, México. \\ ${ }^{c}$ Universidad Autónoma del Estado de Hidalgo, Área Académica de Química, Carr. Pachuca-Tulancingo km 4.5 s/n, Mineral de la Reforma, Hidalgo, México.
}

\begin{abstract}
Resumen
En el programa de la asignatura de Física y Química de superficies se contemplan los fenómenos electrocinéticos, donde figura la electroforesis; la cual es una técnica útil para caracterizar cambios atribuidos a la transformación de biomoléculas como es el caso de las proteínas. Por ello, en el presente trabajo se evaluó la modificación del perfil proteico de lactosuero tratado en un sistema biolectroquímico, haciendo uso de la electroforesis en gel de poliacrilamida (SDS-PAGE). El sistema bioelectroquímico consistió en un electrodo de grafito con una superficie modificada con bacterias (electrodo microbiano), el cual fue puesto en marcha utilizando una técnica cronoamperométrica realizada en un período de 12 horas. Los resultados obtenidos a partir de los perfiles electroforéticos del estado inicial y final del lactosuero indican la presencia de 7 proteínas con pesos moleculares promedio entre 11.83 y $126.50 \mathrm{kDa}$ en ambas muestras. Posteriormente, el análisis estadístico realizado a dichos resultados permitió determinar la transformación de 2 de las 7 proteínas identificadas en el lactosuero.
\end{abstract}

Palabras Clave: Electroforesis, Lactosuero, Proteínas, Grafito, Electrodo microbiano.

\section{Introducción}

Actualmente, la falta del recurso vital: el agua, es una situación alarmante en todo el mundo; por lo que la búsqueda de nuevas alternativas para su cuidado y aprovechamiento son un tema que ha llamado la atención de los investigadores. Sobre todo, cuando se sabe que existen residuos con alto potencial contaminante cuyo tratamiento previo a su vertido en ríos, lagos y lagunas no es efectuado. Tal es el caso del lactosuero; un subproducto generado de la fabricación de quesos, el cual posee elevados valores de demanda química de oxígeno (DQO), debido a su alta carga orgánica (Callejas et al., 2012, García et al., 2012, SAGARPA 2014).

Para la remediación de aguas residuales con contenido orgánico, un tema de vanguardia es el uso de sistemas bioelectroquímicos, donde el uso de electrodos microbianos desempeña una función crucial (Rosenbaum et al., 2011, Revelo et al., 2013). Éstos, son electrodos modificados por la adhesión de microorganismos, más comúnmente bacterias (sésiles), quienes forman una biopelícula sobre la superficie de un electrodo de naturaleza biocompatible y conductora (Reimers et al., 2001). Bajo este arreglo, la bacteria es capaz de donar o aceptar electrones según su naturaleza y polarización impuesta, favoreciendo la transformación de materia orgánica (Rosenbaum et al., 2011, Yaping et al., 2012, Revelo et al., 2013, You-zhao et al., 2014, Revelo et al., 2015, Pérez et al., 2016). Por ello, en el presente trabajo se evaluó la modificación de contenido proteico de lactosuero llevada a cabo mediante un sistema bioelectroquímico.

\section{Materiales y Métodos}

\subsection{Tratamiento de lactosuero mediante un sistema biolectroquímico}

El lactosuero fue tratado mediante un sistema biolectroquímico en batch bajo condiciones anaerobias. Dicho sistema estuvo compuesto por un electrodo microbiano de grafito en barra como electrodo de trabajo, además de un Electrodo de Calomel Saturado como electrodo de referencia y un alambre de platino como contraelectrodo.

Para comenzar el tratamiento del lactosuero, el sistema en batch fue cargado con este residuo, posteriormente se llevó a cabo el proceso biolelectroquímico de transformación mediante una técnica cronoamperométrica, utilizando el electrodo microbiano compuesto por un consorcio bacteriano previamente preparado, caracterizado y adaptado a partir de microorganismos seleccionados de acuerdo al trabajo de Gallegos et al. (2016). Las condiciones electroquímicas consistieron en la imposición de un sobrepotencial $(\eta)$ de -300 $\mathrm{mV}$ Vs OCP durante 12 horas, utilizando un potenciostatogalvanostato Autolab PG-STAT-30 usando el programa computacional NOVA 2.0.

Una vez culminadas las 12 horas de tratamiento bioelectroquímico, el sistema fue descargado y se procedió a 
obtener la muestra correspondiente para su análisis en SDSPAGE.

\subsection{Evaluación del perfil proteico de lactosuero después del tratamiento bioelectroquímico}

Para determinar los cambios producidos en el perfil proteico por el tratamiento bioelectroquímico se realizó una electroforesis en gel de poliacrilamida (SDS-PAGE) del lactosuero tratado bajo estas condiciones y sin tratamiento alguno. La electroforesis fue realizada por duplicado en un equipo BIORAD mini PROTEAN 4 utilizando un gel de separación a $12.5 \%$ de T, una disolución de Tris-Gly-HCl pH= 8.3 como buffer de corrida e imponiendo un potencial de $200 \mathrm{~V}$ hasta que las muestras migraron al frente del gel $(1.35 \mathrm{~h})$.

Durante la separación electroforética se hizo uso de un estándar de amplio rango BIORAD con la finalidad de obtener una curva de calibración que permitiera el cálculo aproximado de los pesos moleculares. Este estándar, contenía las siguientes proteínas: miosina $(200 \mathrm{kDa}), \beta$-galactosidasa $(116.5 \mathrm{kDa})$, fosforilasa $\mathrm{b} \quad(97.4 \mathrm{kDa})$, seroalbúmina $(66.2 \mathrm{kDa}) \quad \mathrm{y}$ ovoalbúmina (45 kDa); así mismo se colocó individualmente aprotinina SIGMA-ALDRICH $(6.5 \mathrm{kDa})$.

Para el análisis de los respectivos geles de poliacrilamida se usó el software de análisis de imagen imageJ, obteniendo así los electroferogramas correspondientes al estándar y muestras en cuestión, determinándose el factor de retención (Rf) y peso molecular aproximado de cada una de las proteínas separadas del lactosuero no tratado y tratado a partir del coeficiente de correlación lineal, la pendiente y la intersección, los cuales fueron obtenidos de los resultados promedio de los estándares utilizados. Una vez obtenidos los pesos moleculares de las proteínas del Lactosuero No Tratado y Lactosuero Tratado se realizó un análisis estadístico, llevado a cabo en el programa Microsoft Excell 2015; en el que se evaluó la variación entre el perfil proteico de la muestra tratada y la muestra no tratada, con sus respectivas desviaciones estándar.

\section{Resultados y Discusión}

En la Figura 1 se muestra la curva de calibración realizada a partir de los pesos moleculares y el $\mathrm{Rf}$ de las proteínas componentes de los estándares utilizados, de la cual se obtuvo un coeficiente de correlación lineal de $98 \%$, una pendiente con un valor de -1.92 y una intersección de 2.55 .

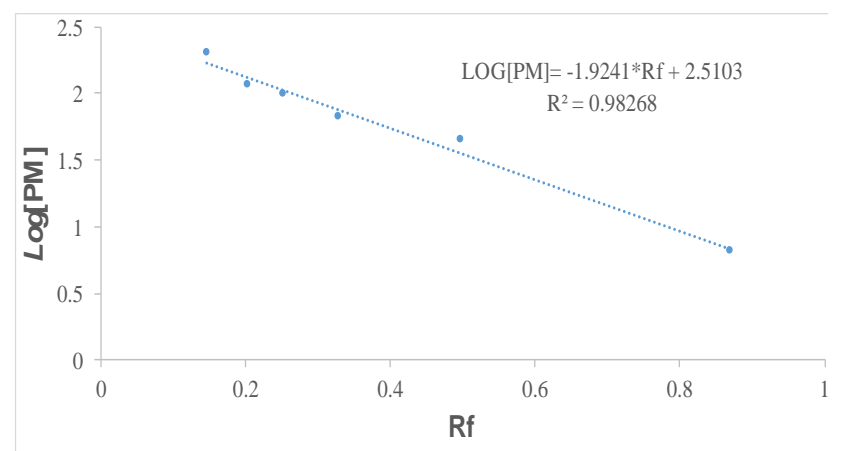

Figura 1: Curva de calibración de Log. de Peso Molecular Vs Rf de las proteínas componentes de los estándares utilizados.
En la Figura 2 y 3 se muestran los perfiles electroforéticos realizados por duplicado al lactosuero tratado y no tratado, destacando que en ambas muestras se identificó la presencia de 7 proteínas, las cuales se presumen como constituyentes del lactosuero.

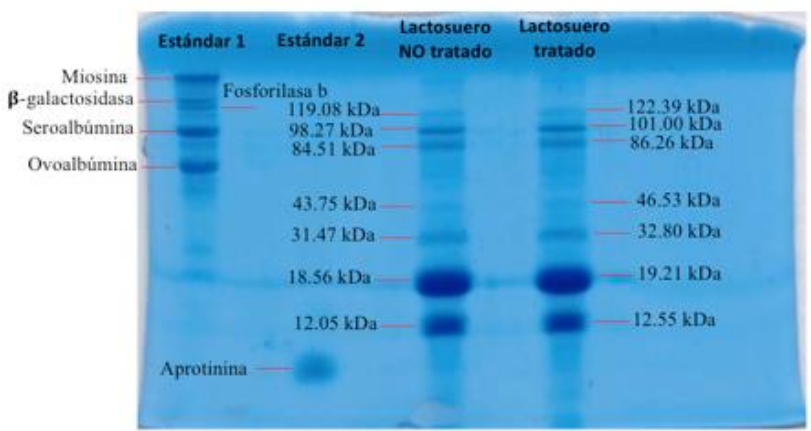

Figura 2: SDS-PAGE (Gel 1) de las muestras de Lactosuero No tratado y Lactosuero Tratado.

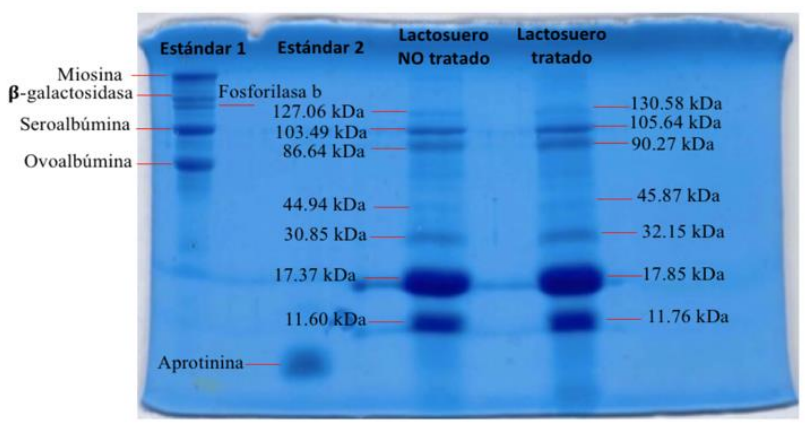

Figura 3: SDS-PAGE (Gel 2) de las muestras de Lactosuero No tratado y Lactosuero Tratado.

A partir de los pesos moleculares obtenidos, se realizó un análisis estadístico comparativo entre las muestras de lactosuero tratadas y no tratadas, ya que los pesos moleculares de las muestras tratatas y no tratadas difieren entre sí en ambos casos, presentándose un incremento en dichos valores para la muestra de lactosuero tratada, tal y como se presenta en las figuras 2 y 3. Dicho análisis estadísitico se presenta en la Figura 4 con sus respectivas desviaciones estándar y fue llevado a cabo con el fin de establecer la transformación de la materia proteica durante el proceso bioelectroquímico.

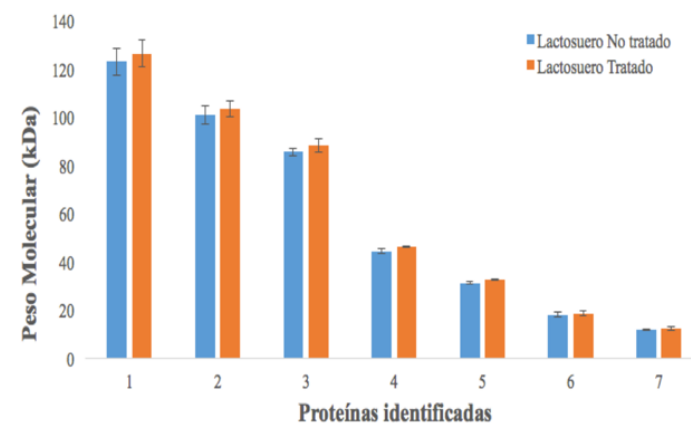

Figura 4: Análisis estadístico de los pesos moleculares de las proteínas identificadas mediante SDS-PAGE en el Lactosuero No Tratado y Lactosuero Tratado. 
El análisis estadístico (Figura 4) mostró que los pesos moleculares correspondientes a las proteínas 1-3, 6 y 7, no presentan indicios de una transformación realizada por parte del sistema bioelectroquímico. Sin embargo, en las proteínas 4 y 5 , se observa que las desviaciones estándar obtenidas al calcular sus pesos moleculares son indicativas de una posible transformación a cargo del sistema bioelectroquímico.

\section{Conclusiones}

Los análisis realizados al lactosuero tratado y sin tratar permitieron determinar que el sistema bioelectroquímico en el que se utilizó un electrodo microbiano de grafito, es útil para la transformación de materia proteica. Así mismo, se determinó que dicha transformación es posible evidenciarla mediante electroforesis en gel de poliacrilamida, aún cuando el sistema bioelectroquímico fue puesto en marcha en un periódo de 12 horas.

\section{English Summary}

\section{ELECTROPHORETIC EVALUATION OF WHEY'S PROTEIN PROFILE MODIFIED THROUGH A BIOELECTROCHEMICAL BATCH SYSTEM}

\section{Abstract}

In the program of the subject of Physics and Chemistry of surfaces are contemplated the electrokinetic phenomena, where electrophoresis appears; Which is a useful technique to characterize changes attributed to the transformation of biomolecules as is the case of proteins. Therefore, the present work evaluated the modification of the protein profile of whey treated in a biolectrochemical system, using polyacrylamide gel electrophoresis (SDS-PAGE). The bioelectrochemical system consisted of a graphite electrode with a bacterial modified surface (microbial electrode), which was started using a chronoamperometric technique performed in a period of 12 hours. The results obtained from the electrophoretic profiles of the initial and final whey's state indicate the presence of 7 proteins with average molecular weights between 11.83 and $126.50 \mathrm{kDa}$ in both samples. Subsequently, the statistical analysis performed on these results allowed the determination of the transformation of 2 of the 7 proteins identified in the whey.

\section{Keywords:}

Electrophoresis, Whey, Proteins, Graphite, Microbial electrode.

\section{Agradecimientos}

Los autores agradecen al CONACyT por las becas otorgadas a los estudiantes para la realización de los estudios de posgrado y al programa de Cátedras CONACyT.

\section{Referencias}

Callejas Hernández, J., Prieto García, F., Reyes Cruz, V. E., Marmolejo Santillán, Y., \& Méndez Marzo, M. (2012). Caracterización fisicoquímica de un lactosuero: potencialidad de recuperación de fósforo. Acta Universitaria, 11-18.
Gallegos Ortega, G., Reyes Cruz, V. E., Cobos Murcia, J. A., Veloz Rodríguez, M. A., Hernández Ávila, J., \& Imbert Palafox, J. L. (2016). Acondicionamiento y caracterización de bacterias electrótrofas para la formación de biopelículas. Tópicos de Investigación en Ciencias de la Tierra y Materiales.

García, J., Elías Castells, J., \& Gaya, J. (2012). Impactos ambientales y energía. En J. García, J. Elías Castells, \& J. Gaya, Tratamiento y valorización energética de residuos (págs. 966-1031). Madrid, España: Ediciones Díaz de Santos.

Pérez-Rodríguez, P., Ovando-Medina, V., Martínez-Amador, S., \& Rodríguez-de la Garza, J. (2016). Bioanode of polyurethane/graphite/polypyrrole composite in microbial fuel cells. Biotechnology and Bioprocess Engineering, 305-313.

Reimers, C., Tender, L. M., Ferting, S., \& Wang, W. (2001). Harvesting Energy from the Marine Sediment-Water Interface. Enviromental Science and Technology, 35(1), 192-195.

Revelo, D. M., Hurtado, N. H., \& Ruiz, J. O. (2013). Celdas de combustible microbianas (CCMS): Un reto para la remoción de materia orgánica y la generación de energía eléctrica. Información tecnológica, 24(6), 17-28.

Revelo, D. M., Hurtado, N., Ruiz, J. O., \& López, S. (2015). Uso de Microorganismos Nativos en la Remoción Simultánea de Materia Orgánica y $\mathrm{Cr}$ (VI) en una Celda de Combustible Microbiana (CCM) de Biocátodo. Información tecnológica, 26(6), 77-88.

Rosenbaum, M., Aulenta, F., Villano, M., \& Angenent, L. T. (2011). Cathodes as electron donors for microbial metabolism: Which extracellular electron transfer mechanisms are involved? Bioresource Technology, 102(1), 324-333.

SAGARPA. (Marzo de 2014). Servicio de información agroalimentaria y pesquera, México. Obtenido de Panorama de la lechería en México: http://www.siap.gob.mx/wpcontent/uploads/boletinleche/bboletleche1trim2014.pdf

Yaping, Z., Jian, S., Yongyou , H., Sizhe , L., \& Qian , X. (2012). Biocathode materials evaluation in microbial fuel cells: A comparison of graphite felt, carbon paper and stainless steel mesh materials. International Journal of Hydrogen Energy, 37(22), 16935-16942.

You-zhao, W., Ai-jie , W., Ai-juan , Z., Wen-zong, L., Li-ping, H., Meiying, X., \& Hu-chun , T. (2014). Electrode as sole electrons donor for enhancing decolorization of azo dye by an isolated Pseudomonas sp. WYZ-2. Bioresource Technology, 530-533. 